\title{
VIDEOPOESIA: UMA POÉTICA DA INTERSEMIOSE
}

\author{
Ana Paula Ferreira*
}

RESUMO:

Este ensaio pretende construir uma possibilidade de análise de videopoemas tendo em vista os processos de semiose $e$ intersemiose, bem como a poética do tecnológico, possibilitados pelas fricções (Vera Casa Nova) entre as artes - nas formalizações críticas de Roland Barthes.

PALAVRAS-CHAVE: videoarte, videopoesia, semiose, intersemiose, fricções.

0 videopoema surge num contexto de trocas quase inevitáveis entre as artes nas últimas décadas. A literatura já não se manifesta somente em livro, mas pode estar em CDs, fitas de vídeo, internet. 0 que ocorre atualmente é uma abertura ao virtual em situações em que a palavra, potencializada em todos os seus parâmetros, já não cabe no livro, como afirma Augusto de Campos (02/2002: 07), numa ampliação cada vez mais nítida da noção de texto.

Várias denominações estão associadas ao experimento a ser analisado: ciberpoesia, poesia artificial, poesia digital, tecnopoesia, poesia eletrônica, clipe poemas. Além disso, a videopoesia está intrinsecamente relacionada à videoarte. Os experimentos de Melo e Castro e de videopoetas contemporâneos, como Arnaldo Antunes, encontram sua contraparte em Nam June Paik e no grupo Fluxus. 0 espaço, a cor, o movimento e demais técnicas, como corte, zoom, (des) sincronização entre imagem e som são elementos sintáticos, elementos semióticos. A tela é pulverizada por flashes de imagens e há freqüentes ruídos. Desde as primeiras experimentações videográficas, principalmente com o surgimento de aparelhos de pós-produção, 0

| Mestre em Letras: Estudos Literários (Área de concentração: Literatura Brasileira), 2003. 


\section{EMTESE}

Belo Horizonte, v. 8, p. I-243, dez. 2004

senso poético já estava incutido e o objetivo de trabalhar poesia em vídeo. 0 primeiro videopoema de Melo e Castro data de 1969 - Roda Lume1- fato contemporâneo às experimentações de Paik. Pode-se afirmar que o videpoema é a tendência da videoarte que apresenta preocupação poético-literária como definidora de seus procedimentos. Pode-se considerar videopoema desde a leitura performática de um poema, exibida em vídeo até experimentos que não apresentam o signo verbal enquanto elemento gráfico na tela

Vera Casa Nova propõe o termo fricções para falar do entrelugar que envolve as artes na contemporaneidade, mais particularmente, cinema e literatura, partindo da noção de "graphos (texto/imagem) enquanto inscrição de signos". No contexto em que é utilizada, a palavra fricções pode ser definida como o atrito entre artes, um "atrito que produz a fagulha" (Casa Nova, 2001: 72-76). Esse atrito pode resultar numa mudança no modo de ver essas artes e num terceiro elemento que, por sua vez, poderia ser o videopoema. A leitura de Casa Nova se encontra em consonância com as idéias de Barthes quando ele defende o intercâmbio entre os objetos e não entre as disciplinas. ${ }^{2}$

Sabendo que o atrito é de ordem sígnica, o que transita entre cinema e literatura, por exemplo, a partir da fricção, são signos em processo de mutação. Ou seja, a partir do atrito, estas duas artes passam a contribuir para um novo processo de significação que já não é mais só literatura ou só cinema, mas um pouco de cada um.

Assim, o videopoema pode ser considerado resultado de processos de semiose e intersemiose entre regimes semióticos diferentes que se encontram num espaço intersticial. Há processos de semiose constituídos não apenas por signos literários, mas por uma conjuntura maior. 0 vídeo é friccionado com a literatura, com o cinema, com a pintura, com a escultura e com as artes gráficas, trazendo para esse suporte e sua linguagem, através da intersecção sígnica, princípios que não the são inerentes. Há o conceito de montagem, advindo do cinema, técnicas de artes gráficas, principalmente nos experimentos atuais, que podem contar com importantes fundamentos da computação. Isso possibilita trabalhar tanto o texto como a imagem na tela de diversas maneiras (cores, montagem, sobreposições, texturas, letras retrabalhadas, dentre outras possibilidades). Há também procedimentos de vídeo, como a intervenção na imagem eletrônica e procedimentos de pintura e escultura, se 
se considerar que a manipulação das imagens se assemelha tanto ao trabalho do pintor quanto ao do escultor - este esculpe uma "escultura eletrônica", por assim dizer. Os processos de significação acontecem via trocas de funções entre signos mistos que vão se metamorfoseando através do encontro com outros signos: "aproximam-se pelas imagens, desdobram-se pela linguagem. Uma arte percute em outra, para Deleuze, ou um texto gera outro texto, para Barthes" (Casa Nova, 2001: 74).

Seguindo o pensamento de Casa Nova, sugiro a palavra e a imagem (também o som) como elementos possibilitadores das fricções no videopoema. Neste sentido, esse experimento pode ser analisado em dois grupos. 0 primeiro é constituído por videopoemas concretistas que, ao modo do poema concreto, mantêm o signo verbal gráfico enquanto núcleo. Os processos de produção se assemelham muito aos da Poesia Concreta, contando, inclusive, com a releitura de poemas desta tendência para 0 vídeo, como em Poesia Visual - Vídeo Poesia $a^{3}$ mediado por Ricardo Araújo. No segundo grupo, os videopoemas que não se encaixam na tendência concretista rompem com a palavra enquanto elemento essencialmente gráfico, propondo experimentos em que a imagem é o fundamento, e não o signo verbal. Este pode aparecer, mas não com os pressupostos anteriores. Um exemplo seria o experimento em que o texto aparece através de uma letra lida ou cantada, como em Janaúba, de Éder Santos. Outro exemplo seria o experimento que não apresenta nenhum poema, nenhum texto, nem oral nem escrito na tela, sendo as imagens a célula nuclear, como em Between, de Cao Guimarães. Nesse sentido, Philadelpho Menezes (1991: 111) se interroga:

[...] é possível se falar numa poesia onde o signo plástico exerça uma função poética (o que, entenda-se, não é o mesmo que um signo visual exercendo uma função plástica numa poesia essencialmente verbal)?

A essa questão acrescento: é possível considerar o videopoema uma manifestação da poesia visual na poética do tecnológico? Há outras formas de manifestação do videopoema que, não utilizando o signo verbal como material concreto, ainda mantêm processos literários?

Em Poesia Visual - Vídeo Poesia têm-se a releitura de poemas que já haviam sido publicados em papel e alguns em holografia. Na transposição para vídeo, o que era sugestão de movimento, passa a ser movimento concreto. 0 sonoro sugerido pelo aspecto formal do significante ganha uma linha de áudio e efeitos de som. A 


\section{EMTESE}

Belo Horizonte, v. 8, p. I-243, dez. 2004

partir dessas potencializações no significante (que percutem na significação) e de invocações sensoriais, este experimento é a tentativa de realização potencializada do fator verbivocovisual da Poesia Concreta; leitura intersemiótica, recriação, transcriação e transdução. É o que Júlio Plaza chama de tradução intersemiótica e que os poetas do Poema-Processo chamam de versão.

Nesse sentido, o conceito barthesiano de leitura (Barthes, 1980: 111) pode ser aplicado. Assim como o leitor, segundo o crítico, busca construir o sentido nas dobras do texto, ao transduzir os poemas para vídeo, os poetas e técnicos que o fizeram procuraram, na abertura que aqueles textos já apresentavam, no que se refere ao suporte, os procedimentos para o experimento videográfico, via fricções. Na versão em vídeo, o que se tem é a fricção dos procedimentos literários já existentes em sua feitura no papel (paronomásia, síntese) com os videográficos (uma linha de áudio e uma linha de imagem que se atravessam causando ressonâncias uma no outra, em conjunto com os efeitos de animação e de edição utilizados).

0 processo pode ser entendido como um desdobramento do "original", algo que tende a ampliar os processos de significação do primeiro texto numa direção ao texto cada vez mais plural. Em "Bomba", "concretização" do movimento explosivo, em "Femme", a iconização dos personagens masculino e sobretudo feminino e em "SOS", a solidão representada pela dimensão abissal.

Nome, de Arnaldo Antunes, apresenta videopoemas de tendência concretista e não concretista. Em "Não tem que", por exemplo, os versos "não tem que/ nem precisa de/ não tem que precisar de/ nem precisa ter que [...]" são compostos por fragmentos do cotidiano e o videopoema é formado por signos verbais e não verbais: faixas de pedestre, sinalização para os motoristas (como o semáforo), placas de publicidade dentre outras. Entram também neste rol imagens, como pneus de caminhão, representando o perigo a que fica exposto quem não respeita as sinalizações. Também há a sugestão das sinalizações como obstáculos no sentido de controladores das ações humanas. Precisa-se ou não de placas? é a pergunta sugerida.

Ainda neste experimento, técnicas de edição caminham, em alguns dos experimentos, para a dissonância, como em "Pessoa". Ao longo do vídeo há o texto poético que pode ser lido na tela, porém, a leitura oral do poeta não é a convencional, havendo uma confusão no espectador que não sabe se lê os sintagmas que atravessam 
a tela, se ouve a leitura do poeta ou se presta atenção ao background que se movimenta em direção contrária à dos signos verbais. Há disfunção do sentido, desfocalização da leitura, construção e desconstrução.

Em se tratando de experimentos não concretistas, o videopoema encontra amadurecimento videográfico em trabalhos como Between (Cao Guimarães, 1999). Como afirma seu autor,

da mesma forma que, na literatura, a célula, o átomo, a coisa fundadora é a palavra, no audiovisual, no cinema, no vídeo, que seja, é a imagem e o som. [...] acho que a poesia deve surgir não da palavra no cinema, mas da imagem, o que seria um cinema poético ou um vídeo poético ${ }^{4}$.

Between tematiza pequenos aspectos do cotidiano nem sempre notados. É 0 que Cao Guimarães chama de "espaço entre as coisas". Entre os acontecimentos notáveis do dia a dia, as chamadas pequenas mortes vão aparecendo na tela através de imagens nítidas, desfocadas ou até mesmo sem referenciais. Cabe, então, ao espectador desvelá-las ao longo da exibição: árvores balançadas pelo vento, faróis de carros desfocados pela chuva e pelos reflexos no chão molhado, imagens refletidas em poças d'água. As imagens são justapostas a uma trilha sonora que varia de sons e ruídos do cotidiano à musica propriamente dita.

Tendo, no videopoema, a possilibidade de trabalhar a poesia fora do suporte livro, o que ocorre é uma virtualização cada vez maior do poema que passa, enquanto imagem eletrônica ou digital, a ser uma espécie fluida e temporalizada. 0 poema pode ser lido ou visto durante sua exibição via varredura eletrônica ou decodificação digital, mas depois não existe mais. Assim como a imagem que 1he dá suporte, o poema não existe no espaço físico, mas no espaço virtual e no tempo. A temporalização advinda com a imagem eletrônica e sua fluidez traz para o processo o princípio da metamorfose; signos em constante mutação.

Desse modo, a partir dos processos de intersemiose, o videopoema pode ser considerado híbrido, o que possibilita uma ampliação do caráter sensitivo em poesia. A junção ou justaposição de signos verbais com visuais (e inclusive sonoros) é uma ruptura marco, pois significa uma desterritorialização ao propor uma visão mais ampla de arte e literatura. As fricções são de tal forma intensas, que tornam difícil a territorialização do experimento. Pode-se levantar a questão de que o 


\section{EMTESE}

Belo Horizonte, v. 8, p. I-243, dez. 2004

videopoema apresenta elementos literários, signos literários, mas não constitui em si, literatura. Porém, não é só vídeo, mas um entrelugar deste com a literatura. Daí a dificuldade de análise. A composição plástica do videopoema indica algo que transcende estes dois suportes. Fazer literatura em vídeo ou fazer vídeo com linguagem literária? No caso do experimento analisado, as duas afirmativas fluem na mesma direção: lidar com um "texto" que não é mais da ordem do discursivo ou do puramente plástico, mas algo que é resultado de processos de hibridização de linguagens.

$\mathrm{Na}$ possibilidade de passar do bi para o tridimensional, a linguagem literária é tomada como subversão, instaurando uma nova modalidade de trabalho com o poético. Muda-se o suporte e, conseqüentemente, a 1 inguagem. Assim como no PoemaProcesso, além do aspecto visual, também participam do poema o caráter táctil e uma acentuada experimentação com signos diversos.

Como as mudanças em arte não esperam sua aceitação pela crítica para continuar acontecendo, embora o videopoema não tenha sido estudado ainda pela crítica literária com o aprofundamento necessário, já podem ser registrados outros processos que potencializam as inovações trazidas pelo vídeo. Das artes plásticas à literatura, várias interfaces, softwares, podem ser utilizados atualmente como ferramentas de trabalho. Mouses, canetas óticas, telas sensitivas e próteses robóticas são ferramentas disponíveis ao artista que pode, inclusive, criar uma obra inteira a partir de algoritmos. "Na arte interativa (AI), o participante da experiência é captado por sensores; comanda robôs, veste macacões, capacetes, luvas; usa óculos especiais, manipula mouses, aciona teclados."(Domingues, 1997: 24)

0 que se pode perceber nas novas possibilidades de manifestação da arte é a ruptura com antigos pressupostos. Nesse sentido, o trabalho coletivo ganha maior destaque e o conceito de autoria se modifica devido ao fato de que na arte interativa, o texto passa a ser obra em devir, "work in progress", como diria James Joyce.

Portanto, as questões envolvendo as novas tecnologias indicam um movimento ascendente da poesia rumo à interatividade. Das vanguardas do início do século XX aos poemas interativos on-line, há uma ampliação de fatores que abrem cada vez mais o texto à pluralidade. Nesse sentido, "quanto mais difícil situar a origem da enunciação, mais plural é o texto. No texto moderno, as vozes são tratadas até a 
negação de qualquer localização: o discurso, ou melhor, a linguagem fala, e é tudo". (Barthes, 1980: 73)

0 poema hibridizado pelos novos aparatos tecnológicos é antidiscursivo. Saindo da área da linguagem verbal, ele está propenso a dialogar com várias formas possiveis de linguagem, exigindo uma nova abordagem que, por sua vez, aponta para a necessidade de uma abertura por parte dos poetas interessados pelo espaço extraliterário ao que o diálogo entre procedimentos de artes diferentes pode oferecer. A literatura "atesta o dilacerar-se das linguagens, inseparável do dilacerar-se das classes: como Liberdade, ela é a consciência desse dilacerar-se e o esforço mesmo que quer ultrapassá-10". (Barthes, 2000: 79)

Marcelo Dolabela ${ }^{5}$ afirma que a poesia, por meio de suas novas formas de expressão, está voltando para o lugar dela. Considerando a literatura como uma intrusa na poesia, para ele, quando a poesia vai para a música, ela está abandonando uma coisa que não é dela. 0 poema não precisa estar ligado estritamente à literatura. Ele deve ser concebido como uma forma aberta a experimentações diversas, independente de se partir da literatura, de estar preso ao papel ou pesquisando numa visão fechada de suporte.

0 videopoema é um exemplo de que tecnologia e arte podem "caminhar" juntas numa troca de recursos cada vez mais visível e dinâmica. Trabalhar com a tecnologia para além da questão do utilitário ou do previsto, conseguir com a máquina resultados para os quais ela não está, a priori, programada. Hoje é possível perceber e delinear o artístico na sinergia entre máquina e homem, racional e sensível, matemática e poesia. 0 poeta passa a ser, cada vez mais, se esta for sua opção, "um designer da linguagem". (Pignatari, 2000: 05-11) 0 que se tem é a realização parcial da profecia de Walter Benjamim de que o poeta do futuro seria uma espécie de poeta iconográfico, um criador de ícones visuais. (Araújo, 1999: 86) 


\section{EM TESE}

Belo Horizonte, v. 8, p. I-243, dez. 2004

NOTAS:

1. Esse trabalho não é mais acessível porque após a transmissão num programa de informação literária foi destruído pela RTP - Cf. MELO e CASTRO. Arte dos Meios e High tech, p. 64.

2. Barthes afirma que "Não são as disciplinas que se devem intercambiar, são os objetos: não se trata de "aplicar" a lingüística do quadro, de injetar um pouco de semiologia na história da arte; trata-se, sim, de anular a distância (a censura) que separa institucionalmente o quadro e o texto. Assistimos ao nascimento de alguma coisa, algo que anulará não só a "literatura", como também a "pintura" (e seus correlatos metalingüísticos, a crítica e a estética), substituindo essas velhas divindades culturais por uma "ergografia" generalizada, o texto como trabalho, o trabalho como texto." Em 0 óbvio e o obtuso, p. 137.

3. Vídeo Poesia-Poesia Visual: trabalhos produzidos no Laboratório de Sistemas Integráveis (LSI) do Departamento de Engenharia Eletrônica da Escola Politécnica da USP e executados a partir da utilização dos seguintes meios: modelagem e renderização, na Silicon Graphics com software Alias Studio; transferência algorítmica dos frames para uma fita de vídeo destino U-Matic e SVHS. Fazem parte do projeto com o mesmo nome, que foi apresentado como tese de doutorado por Ricardo Araújo na Faculdade de Letras da USP (1996).

4. GUIMARÃES. Entrevista cedida em junho de 2003 à Ana Paula Ferreira.

ABSTRACT :

This essay intends to construct a video-poem analysis possibility, regarding the notions of semiology and intersemiology as well as technological poetry, made possible by 'frictions' (Vera Casa Nova) among the arts in Roland Barthes critical formalization.

KEY WORDS: video-art, video-poetry, semiology, intersemiology, frictions.

\section{REFERÊNCIAS BIBLIOGRÁFICAS}

ANTUNES, Arnaldo. Nome. São Paulo: BMG Ariola Discos, 1993.

ARAújo, Ricardo. Poesia Visual - Vídeo Poesia. São Paulo: Perspectiva, 1999.

BARTHES, Roland. o óbvio e o obtuso. 2. reimp. Trad. de Léa Novaes. RJ: N. Fronteira, 1990.

------. O grau zero da escrita. Trad. de Mario Laranjeira. São Paulo: Martins Fontes, 2000.

-_-_. S/Z: uma análise da novela Serrasine, de Honoré Balzac. Trad. de Lisboa: Ed. 70, 1980.

BENJAMIN, Walter. A obra de arte na época de suas técnicas de reprodução. Magia e técnica, arte e política. São Paulo: Brasiliense, 1994. (Obras escolhidas, 1 v.). 
CAMPOS, Augusto. Entrevista. Minas Gerais. Sup. Literário, BH, n. 56, p. 07-16, fev. 2000.

CASA NOVA, Vera. Fricções. Aletria: revista de estudos em literatura. Belo Horizonte, n. 08, p. 72- 76, 2001. Centro de Estudos Literários da Faculdade de Letras da UFMG.

DOMINGUES, Diana. A arte no século XXI: a humanização das tecnologias. São Paulo: Unesp, 1997.

MACHADO, Arlindo. A arte do vídeo. São Paulo: Brasiliense, 1988.

Máquina e imaginário: os desafios das poéticas tecnológicas. 3. ed. São Paulo: Edusp, 2001,

MELO e CASTRO, E. M. O fim visual do século $X X$. São Paulo: Edusp, 1993

Vega, 1998.

Poética dos meios e arte high tech. Lisboa:

MENEZES, Philadelpho. Poesia e visualidade: uma trajetória da poesia brasileira contemporânea. Campinas: Ed da Unicamp, 1991.

PIGNATARI, Décio. Entrevista. Revista CULT: revista brasileira de literatura. São Paulo n. 38, p. 05-11, set. 2000. (Entrevista concedida a Carlos Adriano).

PLAZA, Julio e TAVARES, Mônica. Processos criativos com meios eletrônicos: poéticas digitais. São Paulo: Hucitec, 1998.

PLAZA, Julio Tradução intersemiótica. São Paulo: Perspectiva/ CNPq, 1987.

POPPER, Frank. Art of the Eletronic Age. New Yorque: Thames and Hudson, 1993.

SANTAELA, Lúcia. Imagem: cognição, semiótica e mídia. 3. ed. São Paulo: Iluminuras, 1997.

REFERÊNCIAS VIDEOGRÁFICAS E CDS:

ANTUNES, Arnaldo. Nome. Realizado por: Arnaldo Antunes, Celia Catunda, Kiko Mistrotigo e Zaba Moreau. São Paulo: BMG Ariola Discos, 1993, 1 fita de vídeo (53'), VHS, som, cor, 1 CD, digital, estéreo. Acompanha livro.

ARAUJ0, Ricardo. Vídeo Poesia - Poesia Visual. São Paulo: Laboratório de Sistemas Integráveis (LSI)/ Departamento de Engenharia Eletrônica da Escola Politécnica / USP, 1994. 1 fita de vídeo VHS, som, cor.

GUIMARAES, Cao. Between: inventário de pequenas mortes. $10^{\prime}$, super-8/Dv (realizado para o projeto Objeto do Cotidiano, no Itaú Cultural). BH Pólo Marimbodense de vídeo, 1999. 